\title{
The adapted physical activity as a valuable tool to overcome social prejudice to the disabled persons
}

\author{
LAURA SAVINO, LAURA RIO , FILIPPO GOMEZ PALOMA \\ Department of Human, Philosophical and Education Science, University of Salerno, Italy
}

\begin{abstract}
Savino, L., Rio, L., \& Gomez, F. (2015). The adapted physical activity as a valuable tool to overcome social prejudice to the disabled persons. J. Hum. Sport Exerc., 9(Proc1), pp.S418-S424. The Adapted Physical Activity, in modern times, is defined as the program with an educative target so it promotes the autonomous recovery of the person through direct experience of physicality (Cottini, 2008). The ICF (WHO, 2001) is a guide achieving this objective because it defines disability as the product of the relationship between the health of the person and the context in which he lives. The context creates disability because it doesn't have the appropriate tools to allow the free expression of the person for the different life contexts (Cottini, 2008). Finally the "conquest" consists in the implementation of Adapted Physical Activity. This activity is expressed in the manipulation of the physical context according to the various needs of the person to improve all their dimensions. The TMA test is the methodology used to evaluate the functionality of Adapted Physical Activity to empower the global person's self-esteem. This instrument has favored a primary monitoring to understand the initial condition of the four disabled, involved in the research work, and the whole class group. The results obtained in this first phase were classified as negative according to the American standardized sample. The test had determined how the global self-esteem of the disabled person was influenced by his conditions of marginalization determined by the prejudice that limited action. The A.P.A., during the hours of physical education, has facilitated the achievement of positive results compared to those of departure. These results represent a pratical demonstration of how prejudice is an abstract entity resulting from the lack of people knowledge. In any case the activity has placed all subjects on the same plane to achive a performance, a common target. The person's improvement is the starting point in the understanding of this work. Key words: ADAPTED PHYSICAL ACTIVITY, INTERNATIONAL CLASSIFICATION OF FUNCTIONING, DISABILITY AND HEALTH (ICF), SELF-ESTEEM, AUTONOMY, PREJUDICE.
\end{abstract}

\footnotetext{
Corresponding author. University of Salerno, Via Giovanni Paolo II, 132, 84084 Fisciano SA, Italia

E-mail: riolaura@alice.it

9th INSHS International Christmas Sport Scientific Conference, 4-6 December 2014. International Network of Sport and

Health Science. Szombathely, Hungary.

JOURNAL OF HUMAN SPORT \& EXERCISE ISSN 1988-5202

(C) Faculty of Education. University of Alicante

doi:10.14198/jhse.2015.10.Proc1.34
} 


\section{INTRODUCTION}

The adapted physical activity is defined, in modern times, as the program with an educative target as the objective to attain is to favor the recovery of the residual tasks of the person to prevent the complete loss and promote their full autonomy. It is an opportunity into the area of the valorization of the person's skills through direct experience of physicality.

The idea of the formation of adapted physical activity was already brought in the 40s of ' 900 by Ludwig Guttman (1899-1980) as part of rehabilitation.

The neurosurgeon operated in the Stoke Mandeville's Hospital, near London, with soldiers veterans of World War II. These disabilities were more or less serious and Guttman could prove practically as motor practice and sports were necessary for their rehabilitation.

In fact, initially the adapted physical activity was recognized as rehabilitation but today we can say that the APA is something different from the health rehabilitation.

So the adapted physical activity is a set of the exercises programs to done in group and facing,in particular,at people with chronic diseases and/or deficit of various nature, targeted at the modification and improvement of their lifestyle (Gomez Paloma, Rio \& D’Anna, 2014).

Only in 1973, however, was coined acronym APA and founded the International Federation IFAPA (International Federation of Adapted Physical Activity), with the objective to spreading its principles in many parts of the world through the organization of the international conferences. The primary target of the Federation is the development of research and improvement of the interaction between the theoretical and practical, that is between the work of researchers and the operators (teachers, instructors, physiotherapists and others).

The problem of the IFAPA program was to consider the many types of disabilities. This debate initiated in concrete and organic only in the late ' 80 's, when experts all over the world began a dialogue, exchanging opinions and proposals for definitions, terminologies, classifications and programs. However only in the ' 90 there was a complete and organic definition of adapted physical. It was identified as the set of knowledge and interdisciplinary skills addressed to underline and resolve problems in the specific psychomotor disabilities, to defend the right to health and to an active lifestyle and to develop an appropriate schoolcommunity service realizing the process of inserting and integration.

A great help to the massive spread of the APA was then definitely by the creation of the first trade publication, the Adapted Physical Education Quarterly, who divulged the results of research, of Congresses and practical experiences.

Certainly the achieving of that target is possible by following the guidelines of the ICF (International Classification of Functioning, Disability and Health) which defines disability as the product of the relationship between the health condition of the person and the context in which he lives. The context creates disability because it doesn't have the appropriate tools to allow the free expression of the person for the different life contexts (Cottini \& Rosati, 2008). 
The adapted physical activity puts the disabled, in this case, as the core of the planning because the adaptation must encourage the discovery and the refinement of skills not expressed due to the structural and physical limitations (Raiola, Tafuri \& Gomez Paloma, 2014). The adapted physical activity is a valuable tool to improve the functionality of the person, especially the disabled. On the other hand it is necessary that the adaptation is appropriate to the person with whom you come into contact.

The reason is that it is not the disabled person to adapt to the environment and to the program of physical activity, rather it is the condition to the contrary: the disabled person must be the protagonist, the subject of the activity and not the object.

The basic concept is that the setting in which the person acts should be changed to provide the necessary space for the expression of the ability of everyone. In fact, the ICF adopts a universal approach, for everyone because he uses the concept of human functioning for the lifelong. So the sequence impairmentdisability-handicap is replaced by bio-psycho-social model in which the health of the person is defined by three factors: biological, psychological and social. It's important a particular attention to contextual and social environment in which the person lives.

The functioning approach, however, clarification as disability is the health condition of the person in an unfavorable environment that limiting the person. The disability isn't the subjective condition of the person.

The target of the project work is to support the growth of the self-esteem in disabilities person through the implementation of the adapted physical activity program. The initial problem of the project work is how social prejudice can hinder the free expression of the disabled person but more generally of each person. The prejudice causes in the person a sense of fear that drives him to isolate themselves from the rest of the group because he is not able to make according to the demands of the context. The cause of this condition is to appeal at the person "able-bodied" who precludes himself the opportunity to know each other disabled and the context. The context doesn't have the resources and the different tools to give the correct answer to the different needs of the person.

The problem area, or rather the consequence of the initial problem, is the attitude of closing of the disabled person to any proposed activity within the school environment, particularly in the motor area. The school environment is the first educative institute for the growth and the maturity of the person (Raiola, Scassillo, Parisi \& Di Tore, 2013). For this reason it is necessary to educate young people for understanding the disability field, touching it with his hand, coming into contact with disabled.

The construction of the social relations is limited by prejudice that seems to be predominant among the young people especially at school because they come into contact with each other than himself. The target is to create the same plane on which recognize the other as the person: in this way will there be mutual respect and acceptance. This objective is expressed in the manipulation of the physical context according to the various needs of the person to improve all their dimensions. Certainly the first target is not the final performance, the technical move, but the process that the individuals adopt to facilitate the achievement of a target.

So the motor activity is the promoter of the improvement of the social relations to empower the disabled global self-esteem through social participation favored by the adaptation of the setting. 


\section{MATERIAL AND METHODS}

The project work's objective is to demonstrate how the adapted physical activity can be a valuable tool for overcoming the social prejudice to allow the growth of the disabled self-esteem. So the objective consists in making an activity for the participation of all subjects to the activities proposed during the hours of the physical education. Certainly each activity is planned again on the person's needs: the expression of their skills is functional to the recognition and improvement of these. However, operating in this way, each subject can act with total freedom, thanks to a context that use its resources, adapting to personal need.

The TMA test (Bracken, 2012) is the methodology used to evaluate the functionality of Adapted Physical Activity to empower the global person's self-esteem. This tool is constituted by 6 scales of self-esteem, according to the six areas of the person, for a total of 150 items. The test has favored a primary monitoring to understand the initial condition of the four disabled, involved in the research work and the final evaluation. The items are characterized by the negative and positive character: there are four possible answers and the scoring system varies if it is negative or positive affirmation. The self-esteem measurement is related to the basic concept for which the subject is characterized by multiple dimensions: it's the global self-esteem in relation to the totality of the person. The receivers of the project work are four disabled children of the age group between 11 and 14 years. The predominant disabilities are motor (1) and sensory (3).

The choice of the subjects, receivers of the project, was made by defining the presence of a high number of disabled within the various classes that make up the institute middle school "L. Santarella" in Corato, Bari. Indeed all the classes are taken into consideration for all levels of education. Initially, the sample was detected in the following way:

- define for each level of classes $\left(1^{\wedge}-2^{\wedge}-3^{\wedge}\right)$ the presence of one disabled;

- define for each level of classes $\left(1^{\wedge}-2^{\wedge}{ }^{\wedge}-3^{\wedge}\right)$ the presence of more disabled.

Certainly it wasn't explained to them the objective of the project so as not to influence their actions. The activities were carried out during the hours of physical education, for 2 times a week, with the constant presence of the physical education teacher. The activities were normally: warm-up exercises (such as running around the field) and sports activities such as in particular volleyball and basketball. The objective for the person with physical disabilities was to encourage the participation in the activities through the adaptation of the exercises to the needs of the person (for example, it was crucial to distinguish the various phases of which the volleyball: beaten, crushed, and then receive play the final action). For individuals with sensory disabilities was essential to adapt the instructions and directions to carry out the activities (such as the exercises were represented by the teacher because they were included exactly) (Altavilla, Tafuri \& Raiola, 2014).

In general in all activities the adaptations were proposed to the whole group so that this class could identify with the disabled person and understand his difficulties to act in an unfavorable context. 


\section{RESULTS AND DISCUSSION}

The results obtained were classified according to the American standardized sample.

The test results have proved that, before to the activity, the scale of interpersonal relations represents for all four subjects a weak side. In fact the level of the self-esteem was very negative for the lack of the interaction on the class group. For that reason they didn't participate to the school activity. The level of the self-esteem is negative even the ladder on the successes and failures at school, although it's slightly negative. This condition demonstrates how the children involved are not participating in the activities especially at the hour of physical education where the context doesn't allow them to express themselves fully and freely: you don't feel appreciated as they haven't the ability to act freely. The results, at the conclusion of the activities showed an improvement in the condition of the disabled, which at that time they felt appreciated and recognized as fist people.

This fundamental evolution didn't happen overnight, but it took longer than it was crucial to understand how the target of the school activities was to achieve a common target, putting together their skills, apart from what would have been the end result.

The acquired level of the self-esteem is average: feel part of a group in achieving a common target is a great achievement, but this conquest is not given once and for all rather must be continuous.

Table 1. Score of Entry Test

\begin{tabular}{|c|c|c|c|c|c|c|c|}
\hline \multicolumn{8}{|c|}{ FIRST PERSON } \\
\hline & Interpersonal & Competence & Emotional & Scholasticism & Familylife & Bodylife & Total \\
\hline Raw score & 53 & 69 & 64 & 61 & 83 & 54 & 384 \\
\hline Standard score & 73 & 90 & 87 & 82 & 97 & 76 & 81 \\
\hline $\begin{array}{c}\text { Confidence } \\
\text { interval: } 99 \%\end{array}$ & $61-85$ & $76-104$ & $77-97$ & $70-94$ & 90-104 & $65-87$ & $76-86$ \\
\hline Classification & VN & ITM & ITM & SN & ITM & SN & SN \\
\hline Percentile rank & 4\%ile & 26\%ile & 20\%ile & 12\%ile & 42\%ile & $5 \%$ ile & 11\%ile \\
\hline \multicolumn{8}{|c|}{ SECOND PERSON } \\
\hline & Interpersonal & Competence & Emotional & Scholasticism & Familylife & Bodylife & Total \\
\hline Raw score & 57 & 70 & 70 & 63 & 86 & 54 & 400 \\
\hline Standard score & 77 & 92 & 84 & 84 & 99 & 76 & 85 \\
\hline $\begin{array}{c}\text { Confidence } \\
\text { interval: } 99 \%\end{array}$ & $65-89$ & $78-106$ & 84-104 & $72-96$ & $92-106$ & $65-87$ & $80-90$ \\
\hline Classification & SL & ITM & ITM & SN & ITM & SN & SN \\
\hline Percentile rank & $6 \%$ ile & 29\%ile & $35 \%$ ile & 15\%ile & 48\% ile & $5 \%$ ile & 16\%ile \\
\hline \multicolumn{8}{|c|}{ THIRD PERSON } \\
\hline & Interpersonal & Competence & Emotional & Scholasticism & Familylife & Bodylife & Total \\
\hline Raw score & 71 & 77 & 70 & 65 & 88 & 60 & 421 \\
\hline \multirow{2}{*}{$\begin{array}{l}\text { Standard score } \\
\text { Confidence } \\
\text { interval:99\% }\end{array}$} & 81 & 103 & 94 & 86 & 100 & 82 & 91 \\
\hline & $69-93$ & $89-117$ & $84-104$ & $74-98$ & $93-107$ & $71-93$ & $86-96$ \\
\hline
\end{tabular}




\begin{tabular}{|c|c|c|c|c|c|c|c|}
\hline $\begin{array}{c}\text { Classification } \\
\text { Percentile rank }\end{array}$ & $\begin{array}{c}\text { SN } \\
11 \% \text { ile }\end{array}$ & $\begin{array}{l}\text { ITM } \\
58 \% \text { ile }\end{array}$ & $\begin{array}{c}\text { ITM } \\
35 \% \text { ile }\end{array}$ & $\begin{array}{c}\text { ITM } \\
\text { 17\%ile }\end{array}$ & $\begin{array}{c}\text { ITM } \\
50 \% \text { ile }\end{array}$ & $\begin{array}{c}\mathrm{SL} \\
12 \% \text { ile }\end{array}$ & $\begin{array}{c}\text { ITM } \\
\text { 27\%ile }\end{array}$ \\
\hline \multicolumn{8}{|c|}{ FOURTH PERSON } \\
\hline & Interpersonal & Competence & Emotional & Scholasticism & Familylife & Bodylife & Total \\
\hline Raw score & 52 & 69 & 69 & 62 & 70 & 54 & 376 \\
\hline Standard score & 72 & 90 & 93 & 83 & 85 & 76 & 79 \\
\hline $\begin{array}{c}\text { Confidence } \\
\text { interval:99\% }\end{array}$ & $60-84$ & 76-104 & 83-103 & $71-59$ & 78-82 & $65-87$ & $\begin{array}{l}74- \\
84\end{array}$ \\
\hline Classification & VN & ITM & ITM & SL & $S L$ & $S L$ & SL \\
\hline Percentile rank & 3\%ile & 26\%ile & 33\%ile & $13 \%$ ile & 16\%ile & 5\%ile & $8 \%$ ile \\
\hline
\end{tabular}

LEGEND: Very Negative (VN), Slightly Negative (SN), In the media (ITM)

Table 2. Score of Exit Test

\section{FIRST PERSON}

\begin{tabular}{|c|c|c|c|c|c|c|c|}
\hline & Interpersonal & Competence & Emotional & Scholasticism & Familylife & Bodylife & Total \\
\hline Raw score & 77 & 74 & 78 & 75 & 86 & 66 & 470 \\
\hline Standard score & 102 & 99 & 105 & 104 & 99 & 90 & 104 \\
\hline $\begin{array}{c}\text { Confidence } \\
\text { interval:99\% }\end{array}$ & $90-114$ & $85-113$ & $95-115$ & $92-116$ & $92-106$ & $79-101$ & $\begin{array}{l}99- \\
109\end{array}$ \\
\hline $\begin{array}{l}\text { Classification } \\
\text { Percentile rank }\end{array}$ & $\begin{array}{c}\text { ITM } \\
\text { 56\%ile }\end{array}$ & $\begin{array}{c}\text { ITM } \\
48 \% \text { ile }\end{array}$ & $\begin{array}{c}\text { ITM } \\
64 \% \text { ile }\end{array}$ & $\begin{array}{c}\text { ITM } \\
60 \% \text { ile }\end{array}$ & $\begin{array}{c}\text { ITM } \\
48 \% \text { ile }\end{array}$ & $\begin{array}{c}\text { ITM } \\
26 \% \text { ile }\end{array}$ & $\begin{array}{l}\text { ITM } \\
60 \% \text { ile }\end{array}$ \\
\hline \multicolumn{8}{|c|}{ SECOND PERSON } \\
\hline & Interpersonal & Competence & Emotional & Scholasticism & Familylife & Bodylife & Total \\
\hline Raw score & 73 & 73 & 72 & 70 & 88 & 67 & 443 \\
\hline Standard score & 96 & 96 & 97 & 93 & 100 & 91 & 96 \\
\hline $\begin{array}{c}\text { Confidence } \\
\text { interval: } 99 \%\end{array}$ & 84-108 & $82-110$ & $87-107$ & $81-105$ & $93-107$ & $80-102$ & $\begin{array}{l}91- \\
101\end{array}$ \\
\hline Classification & ITM & ITM & ITM & ITN & ITM & ITM & ITM \\
\hline Percentile rank & 40\%ile & 40\%ile & 42\%ile & 33\%ile & 50\%ile & $27 \%$ ile & 40\%ile \\
\hline
\end{tabular}

\begin{tabular}{|c|c|c|c|c|c|c|c|}
\hline \multicolumn{8}{|c|}{ THIRD PERSON } \\
\hline & Interpersonal & Competence & Emotional & Scholasticism & Familylife & Bodylife & Total \\
\hline Raw score & 76 & 73 & 74 & 70 & 88 & 71 & 452 \\
\hline Standard score & 100 & 105 & 100 & 93 & 102 & 96 & 99 \\
\hline $\begin{array}{c}\text { Confidence } \\
\text { interval:99\% }\end{array}$ & $88-112$ & $91-119$ & $90-110$ & $81-105$ & $95-109$ & $85-97$ & $\begin{array}{l}94- \\
104\end{array}$ \\
\hline Classification & ITM & ITM & ITM & ITM & ITM & ITM & ITM \\
\hline Percentile rank & 50\%ile & 64\%ile & $50 \%$ ile & 33\%ile & $56 \%$ ile & 40\%ile & 48\%ile \\
\hline \multicolumn{8}{|c|}{ FOURTH PERSON } \\
\hline & Interpersonal & Competence & Emotional & Scholasticism & Familylife & Bodylife & Total \\
\hline Raw & 77 & 74 & 78 & 75 & 80 & 66 & 450 \\
\hline Standard score & 102 & 99 & 105 & 104 & 94 & 90 & 98 \\
\hline
\end{tabular}




$\begin{array}{cccccccc}\text { Confidence } & 90-114 & 85-113 & 95-115 & 92-116 & 87-101 & 79-101 & 93- \\ \text { interval:99\% } & \text { ITM } & \text { ITM } & \text { ITM } & \text { ITM } & \text { ITM } & \text { ITM } & \text { ITM } \\ \text { Classification } & 56 \% \text { ile } & 48 \% \text { ile } & 64 \% \text { ile } & 60 \% \text { ile } & 35 \% \text { ile } & 26 \% \text { ile } & 44 \% \text { ile } \\ \text { Percentile rank } & \text { LEGEND: Very Negative }(V N) \text {, Slightly Negative }(S N) \text {, In the media (ITM) }\end{array}$

\section{CONCLUSIONS}

In conclusion, the TMA has established an evolution in self test of the four disabled people. The expected results have been achieved but it is essential that the activity is constant and continuous in time to assure the full expression of the person in all areas of daily life.

The self-esteem of the project recipients was about average, after the conclusion of the activities, according to standardized values Americans considered.

So the test was able to show that the "manipulation" of the context is a variable key for the participation of each subject to any activities in the different contexts of action. In this way each one acquires the knowledge of their skills thanks to the tools offered by the external environment in which it's immersed.

\section{REFERENCES}

1. Altavilla, G., Tafuri, D., \& Raiola, G. (2014). Some aspects on teaching and learning by physical activity. Sport Science, 7(1), pp.7-9.

2. Bracken, B.A. (2012). TMA. Test di valutazione multidimensionale dell'autostima. Trento: Erickson Editore.

3. Causin, P., \& De Pieri, S. (2006). Disabili e rete sociale: modelli e buone pratiche d'integrazione. Milano: Franco Angeli Editore.

4. Cottini, L., \& Rosati, L. (2008). Per una didattica speciale di qualità. Dalla conoscenza del deficit all'intervento inclusivo. Perugia: Editore Morlacchi.

5. Gomez Paloma, F., \& Sgambelluri, R. (2012). La disabilità tra didattica e sport. Napoli: Simone Editore.

6. Gomez Paloma, F., Rio, L., \& D'Anna, C. (2014). Physical self-efficacy in women's artistic gymnastic between recreational and competitive level. Journal of Human Sport and Exercise, 9(1), pp.341-347.

7. Germano, I.S. (2012). La sociologia sportiva: significati e pratiche della sociologia dello sport. Soveria Mannelli (CZ): Rubettino Editore.

8. OMS (2004). ICF. Classificazione Internazionale del Funzionamento, della Disabilità e della Salute. Trento: Editore Erickson.

9. Raiola, G., Scassillo, I., Parisi, F., \& Di Tore, P.A. (2013). Motor imagery as a tool to enhance the didactics in physical education and artistic gymnastic. Journal of Human Sport and Exercise, 8(2), pp.93-97.

10. Raiola, G., Tafuri, D., \& Gomez Paloma, F. (2014). Physical activity and sport skills and its relation to mind theory on motor control. Sport Science, 7(1), pp.52-56. 